\title{
Coleus Root Spent as New Adsorbent for Efficient Removal of Methylene Blue from Aqueous Solution: Kinetics and Isotherm Study
}

\author{
PRADEEP KUMAR PAPEGOWDA $^{* 1}$ and AKHEEL AHMED SYED ${ }^{1,2}$ \\ ${ }^{1}$ Department of Studies in Chemistry, University of Mysore, Manasa Gangotri, \\ Mysuru -570006, India \\ ${ }^{2}$ Icon Professor, University of Malaya, Malaysia \\ pradeeppumadi@gmail.com
}

Received 27 December 2016 / Accepted 15 January 2017

\begin{abstract}
Coleus root spent (CRS) was used as an efficient adsorbent for the removal of methylene blue (MB). Morphological properties of the adsorbent were studied using SEM and FTIR. The adsorption parameters such as initial dye concentration, contact time, $\mathrm{pH}$ and temperature were studied. Langmuir and Freundlich isotherm models were used to explain the adsorption behaviour. Pseudo first order and second order kinetic models were used to study adsorption kinetics. The maximum adsorption capacity value $\left(\mathrm{q}_{\max }=66.66 \mathrm{mg} \mathrm{g}^{-1}\right)$ for Langmuir isotherm was near to the experimental value $\left(\mathrm{Q}_{\max }=58.00 \mathrm{mg} \mathrm{g}^{-1}\right)$. It is confirmed that, CRS is an efficient adsorbent for removal of MB from aqueous solution.
\end{abstract}

Keywords: Methylene blue, Coleus root spent, Biosorbent, Adsorption isotherms, Kinetics

\section{Introduction}

Most of the industries, such as textile, leather tanning, paper, food and plastic use synthetic dyes to colour their products. Textile industry alone consumes $10^{7} \mathrm{~kg}$ per year ${ }^{1}$. A large quantity of the dye will be released with the wastewater of industries during its synthesis, dying process and washing. Dyes are highly coloured compounds and most of them have aromatic structure with low biodegradability. Presence of these dyes in water will harm both aquatic life and human being ${ }^{2,3}$. Dyes in water bodies not only impart colour and toxicity but retard the photosynthetic capacity of the autotrophs by blocking sunlight into aquatic system ${ }^{4}$. It is very necessary to remove dyes from the polluted water to obviate health, ecological and environmental problems. The removal of these dyes from the water has become a challenging task. Several methods have been reported from the researchers, which includes, photo degradation ${ }^{5}$, biodegradation ${ }^{6}$, chemical degradation ${ }^{7}$ and adsorption ${ }^{8}$. Among these methods adsorption is the simple, environmental friendly and economical. Many research papers have been published on the adsorption method for 
the removal of dye from aqueous solution. Authors have tried different class of adsorbents which includes, inorganic ${ }^{9}$, agricultural waste $^{10}$, biological waste $^{11}$, polymers $^{12}$ and industrial waste.

In the present research work, an attempt has been made to use Coleus root spent (CRS) as effective biosorbent for the removal of methylene blue (MB) from aqueous solution. MB is a hazardous dye which causes heart related issues, cyanosis, vomiting, jaundice and quadriplegia in humans ${ }^{13}$. Because of these ill effects of $\mathrm{MB}$ it is imperative to remove from water bodies. CRS is found to be cheap and effective adsorbent for the removal of MB from aqueous solutions. Coleus forskohlii (Lamiaceae) is a perennial herb, 1-2 ft. high with a thick root stalk, distributed Kumaon and Nepal and in Deccan peninsula ${ }^{14}$. After extraction of forskolin from the roots of C. forskohlii a large quantity of waste is generated and this has no commercial/fertilizer value. Hence, an attempt has been made to use CRS as an efficient adsorbent for dye removal. Various factors affecting adsorption capacity like initial concentration of dye, temperature and $\mathrm{pH}$ was evaluated.

\section{Experimental}

Analytical grade Methylene blue (LobaChemie, Mumbai, India) was used in this work. Stock solution of $1000 \mathrm{ppm}$ of dye solution was prepared in distilled water and solution of required concentration was prepared by diluting stock solution.

\section{Adsorbent}

The Coleus spent used in this work was supplied from nutraceutical industries. Industrially processed spent material was ground to fine powder and washed thoroughly with distilled water to remove chemical and other impurities. Washed spent was dried in sunlight and passed through sieve again dried in hot air oven at $60^{\circ} \mathrm{C}$ for 24 hours and stored in air tight containers.

\section{Characterization of adsorbent}

Coleus was characterized using scanning electron microscope (Hitachi S3400N, Japan). Absorption spectra were obtained and the spectra of the samples were recorded using Fourier transform infrared spectroscopy (FTIR, PerkinElmer-Spectrum, USA) over the range 4000-400 $\mathrm{cm}^{-1}$.

\section{Adsorption studies}

Dye removal experiments with CRS were carried out by batch experiments in $250 \mathrm{~mL}$ flasks in an orbital shaker incubator at $140 \mathrm{rpm}$. In each batch experiment, $50 \mathrm{~mL}$ dye solution of known concentration (10-100 $\left.\mathrm{mg} \mathrm{L}^{-1}\right)$ and known amount $(0.05 \mathrm{~g})$ of spent was taken in $250 \mathrm{~mL}$ flask at constant temperature. Kinetic studies were carried out at three different initial dye concentrations 25,50 and $100 \mathrm{mg} \mathrm{L}^{-1}$ using $0.05 \mathrm{~g}$ dose of spent and agitated for the fixed time intervals. The effect of the solution $\mathrm{pH}$ on $\mathrm{MB}$ removal was investigated over a $\mathrm{pH}$ range of 4-11. The solution of $\mathrm{pH}$ was measured by $\mathrm{pH}$ meter (Systronics 802). The $\mathrm{pH}$ was adjusted using dilute $\mathrm{HCl}$ and $\mathrm{NaOH}$ solution. After adsorption, the $\mathrm{pH}$ of the dye remains in the solution was adjusted to $\mathrm{pH} 4$ and measured at the maximum wavelength of $\mathrm{MB}\left(\lambda_{\max }=618 \mathrm{~nm}\right)$ using double beam UV-Vis spectrophotometer (Systronics 166). The adsorbed amount of MB at equilibrium $\mathrm{q}_{\mathrm{e}}$ $\left(\mathrm{mg} \mathrm{g}^{-1}\right)$ was determined.

$$
\mathrm{q}_{\mathrm{e}}=\left(\mathrm{C}_{0}-\mathrm{C}_{\mathrm{e}}\right) \mathrm{V} / \mathrm{W}
$$

All tests were performed in triplicate to ensure the reproducibility of the results, the mean of the measurements was reported. 


\section{Results and Discussion}

Scanning electron microscopy (SEM)

The SEM images of CRS before and after adsorption are presented in Figure 1 and 2 respectively. Morphology of CRS is complex with porous structure which has changed significantly with adsorption.

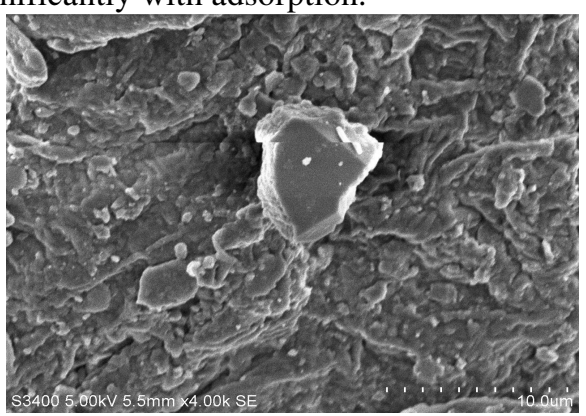

Figure 1. SEM image of CRS before adsorption

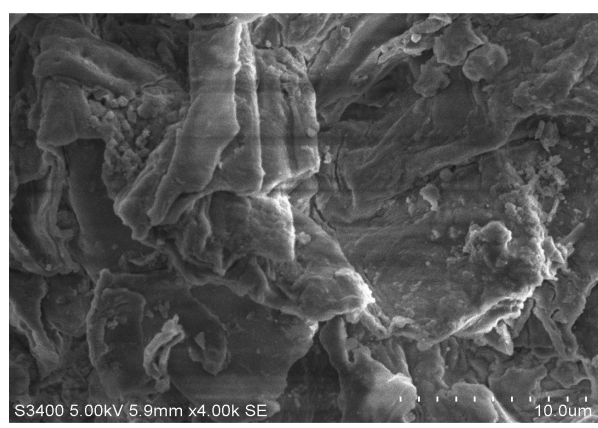

Figure 2. SEM image of CRS after adsorption

Fourier transform infrared spectroscopy (FTIR)

IR spectra of CRS (Figure 3) give the information about the functional groups present. A band at $3423 \mathrm{~cm}^{-1}$ is due to stretching of hydroxyl groups of cellulose, hemicelluloses and lignin that are present in CRS. It shows a prominent $\mathrm{C}-\mathrm{H}$ stretching absorption around $2926 \mathrm{~cm}^{-1}$. Absorption bands due to $\mathrm{C}=\mathrm{C}$ stretching were found at $1627 \mathrm{~cm}^{-1}, 1638 \mathrm{~cm}^{-1}$ and $1652 \mathrm{~cm}^{-1}$. The bands at $1374 \mathrm{~cm}^{-1}$ and $1246 \mathrm{~cm}^{-1}$ are due to $\mathrm{C}-\mathrm{O}$ vibrations and $\mathrm{O}-\mathrm{H}$ bending. Bands at $1325 \mathrm{~cm}^{-1}$ and $1160 \mathrm{~cm}^{-1}$ are due to $\mathrm{OH}$ bending and $\mathrm{C}-\mathrm{O}$ vibration respectively. The bands of $\mathrm{C}-\mathrm{O}-\mathrm{H}$ and $\mathrm{C}-\mathrm{O}-\mathrm{C}$ stretching were found at $1103 \mathrm{~cm}^{-1}$ and $1031 \mathrm{~cm}^{-1}$ respectively ${ }^{15}$.

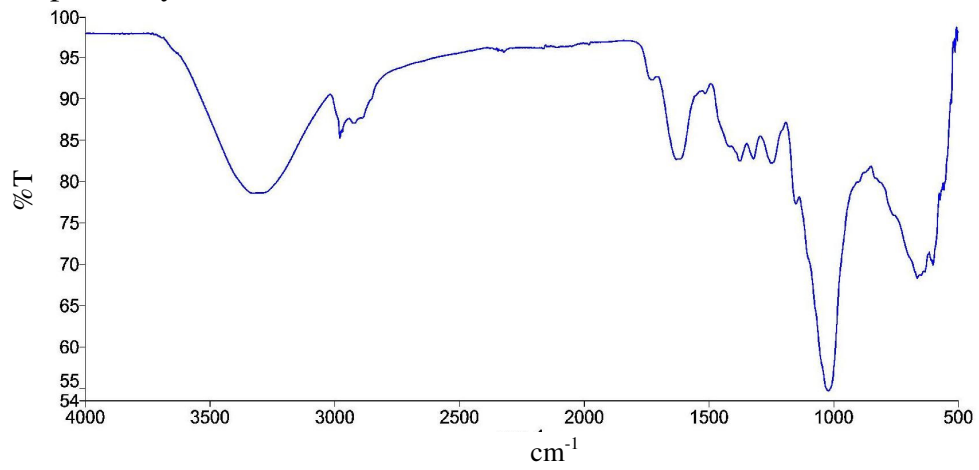

Figure 3. IR spectra of CRS

\section{Effect of initial concentration}

The adsorption of dye was increased from $8-58 \mathrm{mg} \mathrm{g}^{-1}$ for CRS with the increase in dye concentration from 10 to $80 \mathrm{mg} \mathrm{L}^{-1}$. This may be related to an increase in the driving force of the concentration gradient with the increase in the initial MB concentration ${ }^{16}$. Further increase in the initial concentration of dye above $80 \mathrm{mg} \mathrm{L}^{-1}$ will not change the $\mathrm{q}_{\mathrm{e}}$ considerably because of the saturation of the adsorbent (Figure 4). 


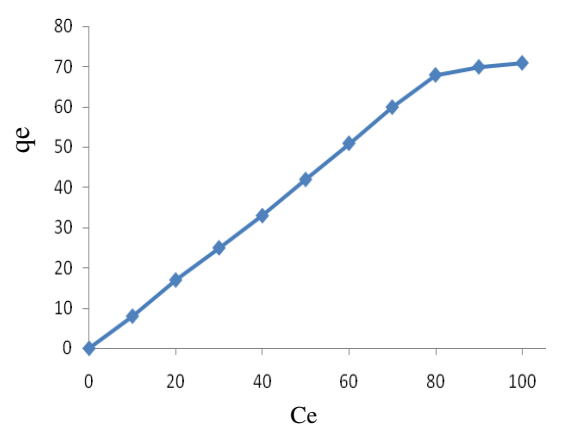

Figure 4. Effect of initial MB concentration

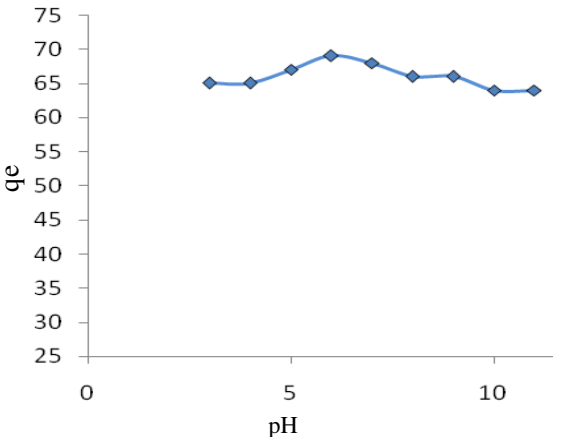

Figure 5. Effect of $\mathrm{pH}$

\section{Effect of initial $\mathrm{pH}$}

The $\mathrm{pH}$ is an important parameter that affects adsorption. To study the effect of $\mathrm{pH}$ on the adsorption of MB onto CRS, the experiments were performed at initial dye concentration of $80 \mathrm{mg} \mathrm{L}^{-1}$ and adsorbent dosage of $0.05 \mathrm{~g} / 100 \mathrm{~mL}$ for equilibrium time of 2 hours at $25 \mathrm{C}$. The amount of dye adsorbed in the $\mathrm{pH}$ range of 3-11 was shown in the Figure 5. The solution $\mathrm{pH}$ affects both aqueous chemistry and binding sites on the surface of the adsorbents. It is observed from the experiments that, the adsorption increases from $\mathrm{pH} 5$, reaches maximum at $\mathrm{pH} 6$ and again decreases gradually. It is clear that, $\mathrm{pH}$ range 5-7 is favourable for the adsorption of MB onto CRS. Decrease in adsorption at lower $\mathrm{pH}$ may be due to competition of $\mathrm{H}^{+}$ions with cationic dye molecules ${ }^{17}$. Some authors have reported the increase in adsorption of MB above the $\mathrm{pH} 5^{18}$.

\section{Effect of time}

The amount of MB adsorbed as a function of contact time is represented in Figure 6. It shows that the MB adsorption was fast at the initial stage of the contact time and then became slower near the equilibrium time. This phenomenon was due to the availability of large number of vacant sites on the surface of adsorbent. Near the equilibrium, rate of the adsorption decreases due the slow pore diffusion of the MB molecules into the adsorbents ${ }^{19}$.

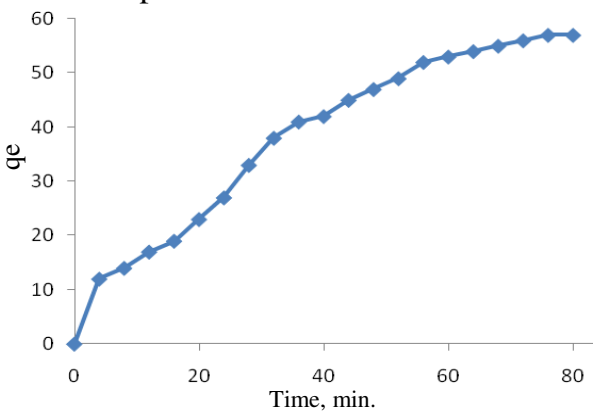

\section{Adsorption isotherm}

Figure 6. Effect of time

Two commonly used adsorption isotherms, Langmuir and Freundlich isotherms were used to explain the interaction of adsorbate and adsorbent (Figures $7 \&$ 8). Langmuir isotherms explain the monolayer adsorption on surface containing limited number of sites. Freundlich isotherms describe adsorption on surface having heterogeneous energy distribution. 


$$
\begin{aligned}
\text { Langmuir isotherm: } & \mathrm{Ce} / \mathrm{q}_{\mathrm{e}}=\left(1 / \mathrm{bq}_{\max }\right)+\left(1 / \mathrm{q}_{\max }\right) \mathrm{Ce} \\
\text { Freundlich isotherm: } & \ln \mathrm{q}_{\mathrm{e}}=\ln \mathrm{KF}+(1 / \mathrm{n}) \ln \mathrm{Ce}
\end{aligned}
$$

Where $C \mathrm{e}$ is the equilibrium concentration of the adsorbate $\left(\mathrm{mg} \mathrm{L}^{-1}\right), \mathrm{q}_{\mathrm{e}}$ is the amount of dye at equilibrium in unit mass of adsorbent $\left(\mathrm{mg} \mathrm{g}^{-1}\right), \mathrm{q}_{\max }$ and $\mathrm{b}$ are the Langmuir constants related to adsorption capacity $\left(\mathrm{mg} \mathrm{g}^{-1}\right)$ and adsorption energy $\left(\mathrm{L} \mathrm{mg}^{-1}\right)$, respectively. $\mathrm{KF}$ and $\mathrm{n}$ are the Freundlich constants related to adsorption capacity $\left(\mathrm{mg} \mathrm{g}^{-1}\left(\mathrm{mg} \mathrm{L}^{-1}\right)^{-1 / n}\right)$ and adsorption intensity of adsorbent, respectively.

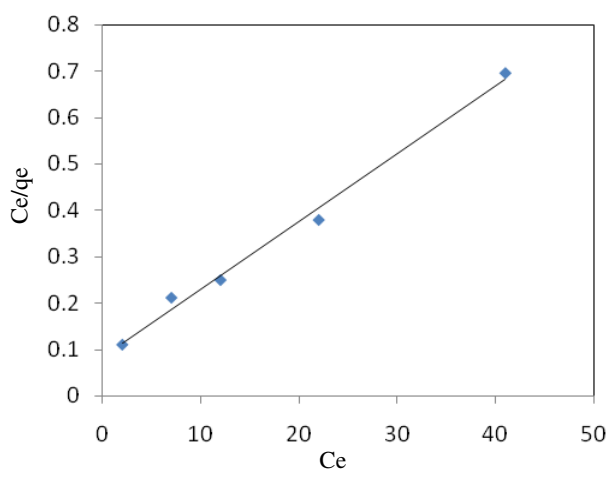

Figure 7. Langmuir isotherm

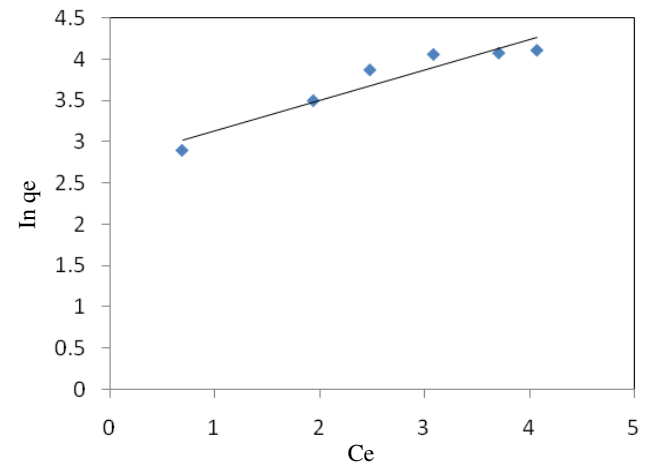

Figure 8. Freundlich isotherm

Langmuir model fits best for the obtained experimental data with regression coefficient $\left(\mathrm{R}^{2}\right)$ 0.996, which indicates the adsorption of MB onto CRS is monolayer, in which all molecules have equal enthalpies and activation energies ${ }^{20}$. Feasibility of this isotherm could be understood from the value of $\mathrm{R}_{\mathrm{L}}$, which indicate the shapes of isotherm to be either favourable $(0<R L<1)$, unfavourable $(R L>1)$ or irreversible $(R L=0)^{21}$. The calculated $R \mathrm{~L}$ value $(0.0426)$ indicates that the adsorption of MB onto CRS is favorable.

\section{Kinetic Models}

\section{Kinetics of adsorption}

Analysis of the kinetic data is important in any adsorption processes, since the kinetics describes the rate of adsorption which helps to predict the mechanism of the process and rate controlling steps.

In the present study, Pseudo-first order and pseudo-second order kinetic models have been used to test the experimental data.

\section{Pseudo-first order kinetic model}

The differential rate equation is

$$
\mathrm{dq}_{\mathrm{t}} / \mathrm{dt}=\mathrm{k}_{1}\left(\mathrm{q}_{\mathrm{e}}-\mathrm{q}_{\mathrm{t}}\right)
$$

Where $\mathrm{q}_{\mathrm{t}}$ and $\mathrm{q}_{\mathrm{e}}$ are the amounts of dye adsorbed at time $\mathrm{t}(\mathrm{mg} / \mathrm{g})$ and at equilibrium $(\mathrm{mg} / \mathrm{g})$, respectively and $\mathrm{k}_{1}$ is the pseudo-first order rate constant $\left(\mathrm{min}^{-1}\right)$. Integrating the above equation using the boundary condition, $\mathrm{q}_{\mathrm{t}}=0$ at $\mathrm{t}=0$ leads to:

$$
\log \left(\mathrm{q}_{\mathrm{e}}-\mathrm{q}_{\mathrm{t}}\right)=\log \mathrm{q}_{\mathrm{e}}-\left(\mathrm{k}_{\mathrm{l}} / 2.303\right) \mathrm{t}
$$

The values of $\mathrm{k}_{1}$ and $\mathrm{q}_{\mathrm{e}}$ were calculated from the slopes and intercepts of the linear plots of $\log \left(\mathrm{q}_{\mathrm{e}}-\mathrm{q}_{\mathrm{t}}\right)$ vs. $\mathrm{t}$ (Figure 9), respectively and presented in Table 2.

\section{Pseudo-second order kinetic model}

The pseudo-second order kinetic model is represented as: 


$$
\mathrm{dq}_{\mathrm{t}} / \mathrm{dt}=\mathrm{k}_{2}\left(\mathrm{q}_{\mathrm{e}}-\mathrm{q}_{\mathrm{t}}\right)^{2}
$$

Where $\mathrm{q}_{\mathrm{t}}$ and $\mathrm{q}_{\mathrm{e}}$ are the amount of dye adsorbed at time $\mathrm{t}(\mathrm{mg} / \mathrm{g})$ and at equilibrium $(\mathrm{mg} / \mathrm{g})$, respectively and $\mathrm{k}_{2}$ is the pseudo-second order rate constant $\left(\mathrm{g} \mathrm{mg}^{-1} \mathrm{~min}^{-1}\right)$. Integrating the above equation using the boundary condition, $\mathrm{q}_{\mathrm{t}}=0$ at $\mathrm{t}=0$ leads to:

$$
\mathrm{t} / \mathrm{q}_{\mathrm{t}}=1 / \mathrm{k}_{2} \mathrm{q}_{\mathrm{e}}^{2}+\mathrm{t} / \mathrm{q}_{\mathrm{e}}
$$

The values of $\mathrm{k}_{2}$ and $\mathrm{q}_{\mathrm{e}}$ were calculated from intercepts and slopes of the linear plots of $\mathrm{t} / \mathrm{q}_{\mathrm{t}} v s . \mathrm{t}$ (Figure 10), respectively and presented in Table 1 . Table 1 shows that the calculated $\mathrm{q}_{\mathrm{e}}$ values are very close to that of experimentally obtained $\mathrm{q}_{\mathrm{e}}$ and the values of correlation coefficients $\left(\mathrm{R}^{2}\right)$ are closer to unity confirms that adsorption of MB on CRS follows pseudofirst order kinetics. From the kinetic constants (Table 2), it is clear that pseudo first-order is better fits with the experimental data than pseudo second-order.

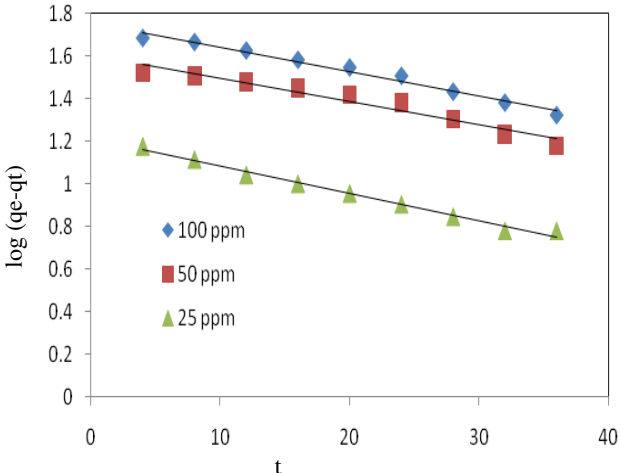

Figure 9. Pseudo-first order kinetics

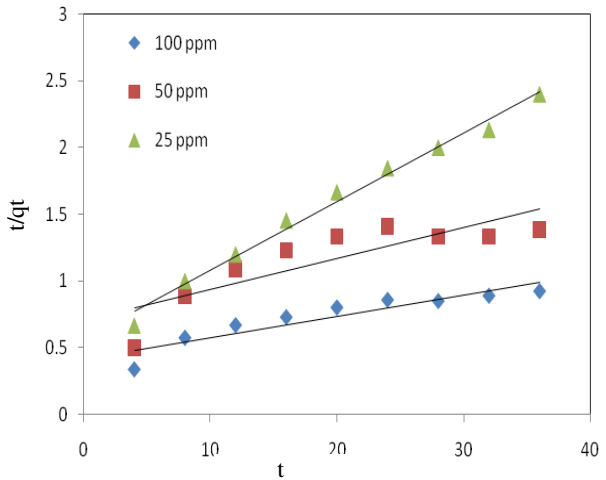

Figure 10. Pseudo-second order kinetics

Table 1. Isotherm parameters for the adsorption of MB onto CRS

\begin{tabular}{ccccccc}
\hline & \multicolumn{3}{c}{ Langmuir constants } & \multicolumn{3}{c}{ Freundlich constants } \\
\hline $\mathrm{q}_{\max }$ & $\mathrm{b}$ & $\mathrm{R}_{\mathrm{L}}$ & $\mathrm{R}^{2}$ & $\mathrm{~K}_{\mathrm{F}}$ & $\mathrm{n}$ & $\mathrm{R}^{2}$ \\
66.66 & 0.187 & 0.0426 & 0.996 & 15.9 & 2.392 & 0.908 \\
\hline
\end{tabular}

Table 2. Kinetic parameters

\begin{tabular}{cccccccc}
\hline Initial dye & $\mathrm{q}_{\mathrm{e}}$ & \multicolumn{3}{c}{ Pseudo-first order } & \multicolumn{3}{c}{ Pseudo-second order } \\
\cline { 3 - 8 } Concentration, mg/L & $\exp$ & $\mathrm{q}_{\mathrm{e}}$ cal & $\mathrm{k}_{1}$ & $\mathrm{R}^{2}$ & $\mathrm{q}_{\mathrm{e}}$ cal & $\mathrm{K}_{2}$ & $\mathrm{R}^{2}$ \\
\hline 25 & 21 & 19 & 0.0506 & 0.0 .963 & 1.838 & 7.046 & 0.946 \\
50 & 41 & 43 & 0.0276 & 0.919 & 1.416 & 21.671 & 0.707 \\
100 & 59 & 73 & 0.0253 & 0.917 & 2.392 & 11.648 & 0.849 \\
\hline
\end{tabular}

\section{Conclusion}

In the present study Coleus root spent, has been used as an eco-friendly and cost-effective biosorbent for the remediation of Methylene Blue, a toxic dye. Maximum adsorption capacity was $\mathrm{q}_{\max }=58.00 \mathrm{mg} / \mathrm{g}$ and it is close to what obtained by Langmuir $\left(\mathrm{q}_{\max }=66.66 \mathrm{mg} / \mathrm{g}\right)$ with correlation coefficient $\left(\mathrm{R}^{2}\right)$ of 0.996 . The experimental data fitted perfectly well with pseudo-first order kinetic model. Possible mechanisms of interactions that can occur in MBCRS system have been discussed. It has been proved that, CRS can be used as a fast and effective adsorbent for the removal of MB from aqueous solutions.

\section{Acknowledgment}

The authors gratefully acknowledge University Grants Commission, Government of India for the award of Research Fellowship in Science for meritorious students. 


\section{References}

1. Hameed B H, Ahmad A A and Aziz N, Chem Eng J., 2007, 133(1-3), 195-203; DOI:10.1016/j.cej.2007.01.032

2. Baek Mi-Hwa, Ijagbemi Christianah Olakitan, O Se-Jin and Kim Dong-Su, J Hazard Mater., 2010, 176(1-3), 820-828; http://dx.doi.org/10.1016/j.jhazmat.2009.11.110

3. Pradeep Sekhar C, Kalidhasan S, Rajesh Vidya and Rajesh N, Chemosphere, 2009, 77, 842-847; DOI:10.1016/j.chemosphere.2009.07.068

4. Shamsizadeh A, Ghaedi M, Ansari A, Azizian S and Purkait M K, J Mol Liq., 2014, 195, 212-218; DOI:10.1016/j.molliq.2014.02.035

5. Aliyan Hamid, Fazaeli Razieh and Jalilian Rahil, Appl Surf Sci., 2013, 276, 147-153; DOI:10.1016/j.apsusc.2013.03.049

6. Jasińska Anna, Różalska Sylwia, Bernat Przemysław, Paraszkiewicz Katarzyna and Długoński Jerzy, Int Biodeterior Biodegradation, 2012, 73, 33-40; DOI:10.1016/j.ibiod.2012.06.025

7. Baek Mi-Hwa, Ijagbemi Christianah Olakitan and Kim Dong-Su, J Environ Sci Health Part A, 2010, 45(5), 630-636; DOI:10.1080/10934521003595779

8. Akar Emine, Altinişik Aylin and Seki Yoldaş, Ecol Eng., 2013, 52, 19-27; DOI:10.1016/j.ecoleng.2012.12.032

9. Solís-Casados D, Escobar-Alarcón L, Fernández M and Valencia F, Fuel, 2013, 110, 17-22; DOI:10.1016/j.fuel.2012.10.042

10. Jalil A A, Triwahyono S, Yaakob M R, Azmi Z Z A, Sapawe N, Kamarudin N H N, Setiabudi H D, Jaafar N F, Sidik S M, Adam S H and Hameed B H, Bioresour Technol., 2012, 120, 218-224; DOI:10.1016/j.biortech.2012.06.066

11. Singh Anita, Manju, Rani Suman and Bishnoi Narsi R, Ecol Eng., 2012, 47, 291-296; DOI:10.1016/j.ecoleng.2012.07.001

12. Sarkar Amit Kumar, Pal Aniruddha, Ghorai Soumitra, Mandre N R and Pal Sagar, Carbohydr Polym., 2014, 111, 108-115; DOI:10.1016/j.carbpol.2014.04.042

13. Yi Ju-Zhen and Zhang Li-Ming, Bioresour Technol., 2008, 99, 2182-2186; DOI:10.1016/j.biortech.2007.05.028

14. Kavitha C, Rajamani K and Vadivel E, J Med Plant Res., 2010, 4, 278-285

15. Mas Haris MRH and Sathasivam K, Am J Appl Sci., 2009, 6(9), 1690-1700; DOI:10.3844/ajassp.2009.1690.1700

16. Hameed B H, Mahmoud D K and Ahmad A L, Colloids Surfaces A, Physicochem Engg Aspect., 2008, 316(1-3), 78-84; DOI:10.1016/j.colsurfa.2007.08.033

17. Garg V K, Kumar Rakesh and Gupta Renuka, Dyes Pigm, 2004, 62(1), 1-10; DOI:10.1016/j.dyepig.2003.10.016

18. Zohre Shahryari, Ataallah Soltani Goharrizi and Mehdi Azadi, Int J Water Res Environ Eng., 2010, 2, 016-028.

19. Shaibu Solomon, Adekola Folahan, Adegoke Halimat and Ayanda Olushola, Materials, 2014, 7(6), 4493-4507; DOI:10.3390/ma7064493

20. Hameed B H and El-Khaiary M I, J Hazard Mater., 2008, 157, 344-351; DOI:10.1016/j.jhazmat.2007.12.105

21 Sartape Ashish S, Mandhare Aniruddha M, Jadhav Vikas V, Raut Prakash D, Anuse Mansing A and Kolekar Sanjay S, Arabian J Chem., 2013;

DOI:10.1016/j.arabjc.2013.12.019 